\title{
PEMANFAATAN AUGMENTED REALITY SEBAGAI MEDIA PEMBELAJARAN
}

\author{
IImawan Mustaqim \\ Fakultas Teknik, Universitas Negeri Yogyakarta \\ email: ilmawan@staff.uny.ac.id
}

\begin{abstract}
Abstrak
Augmented Reality (AR) dapat didefinisikan sebagai sebuah teknologi yang mampu menggabungkan benda maya dua dimensi atau tiga dimensi ke dalam sebuah lingkungan yang nyata kemudian memunculkannya atau memproyeksikannya secara real time. AR dapat digunakan untuk membantu memvisualisasikan konsep abstrak untuk pemahaman dan struktur suatu model objek. Beberapa aplikasi AR dirancang untuk memberikan informasi yang lebih detail pada pengguna dari objek nyata. Media merupakan sebuah alat atau objek yang berfungsi sebagai penghubung antara penerima dan pengirim pesan.

Media pembelajaran merupakan suatu alat perantara antara pendidik dengan peserta didik dalam pembelajaran yang mampu menghubungkan, memberi informasi dan menyalurkan pesan sehingga tercipta proses pembelajaran efektif dan efisien. Media pembelajaran mengakibatkan terjadinya sebuah komunikasi antara pendidik dan peserta didik dalam proses pembelajaran. Apabila dalam proses pembelajaran tidak menggunakan media maka tidak akan terjadi proses pembelajaran.

Pemanfaatan media pendidikan menggunakan Augmented Reality dapat merangsang pola pikir peserta didik dalam berpikiran kritis terhadap sesuatu masalah dan kejadian yang ada pada keseharian, karena sifat dari media pendidikan adalah membantu peserta didik dalam proses pembelajaran dengan ada atau tidak adanya pendidik dalam proses pendidikan, sehingga pemanfaatan media pendidikan dengan augmented reality dapat secara langsung memberikan pembelajaran dimanapun dan kapanpun peserta didik ingin melaksanakan proses pembelajaran. Media Pembelajaran AR dapat memvisualisasikan konsep abstrak untuk pemahaman dan struktur suatu model objek memungkinkan AR sebagai media yang lebih efektif sesuai dengan tujuan dari media pembelajaran.
\end{abstract}

Kata kunci: augmented reality, media pembelajaran

\begin{abstract}
Augmented Reality (AR) can be defined as a technology that can combine virtual objects two-dimensional or three-dimensional into a real environment and then bring it or project it in real time. AR can be used to help visualize abstract concepts for the understanding and the structure of an object model. Some AR application designed to provide more detailed information on the user of the real object. Media is a tool or object that serves as a liaison between the recipient and the sender of the message.

Learning Media is an intermediary tool between educators with learners in the learning that is able to connect, inform and distribute the messages so as to create an effective and efficient learning process. Instructional media resulting in a communication between educators and learners in the learning process. If the learning process does not use the media then there will be a learning process.

Implementation media education using Augmented Reality can be stimulate the mindset of students in critical thinking about something issues and events that exist in everyday life, because of the nature of the medium of education is to help learners in the learning process with the presence or absence of teachers in the educational process, so that the use of the media augmented education with reality can directly provide learning wherever and whenever the learner wants to implement the learning process. Learning Media AR can visualize abstract concepts for the understanding
\end{abstract}


and the structure of an object model enables the AR as a more effective media in accordance with the purpose of learning media.

Keywords : augmented raeality, utilzation of instructional media

\section{PENDAHULUAN}

Augmented Reality adalah teknologi yang menggabungkan benda maya dua dimensi atau tiga dimensi kemudian lalu memproyeksikan benda maya tersebut dalam waktu nyata (James R. Valino, 1998). Augmented Reality didefinisikan sebagai teknologi yang menggabungkan dunia nyata dengan dunia maya, bersifat interaktif menurut waktu nyata, serta berbentuk animasi tiga dimensi (Azuma, 1997). Dengan demikian Augmented Reality (AR) dapat didefinisikan sebagai sebuah teknologi yang mampu menggabungkan benda maya dalam dua dimensi atau tiga dimensi ke dalam sebuah lingkunagn yang nyata kemudian memunculkannya memproyeksikannya secara real time.

AR merupakan sebuah konsep menggabungkan dunia maya dengan dunia nyata untuk menghasilkan informasi dari data yang diambil dari sebuah sistem pada objek nyata yang ditunjuk sehingga batas antara keduanya menjadi semakin tipis. AR dapat menciptakan interaksi antara dunia nyata dengan dunia maya, semua informasi dapat ditambahkan sehingga informasi tersebut ditampilkan secara real time seolah-olah informasi tersebut menjadi interaktif dan nyata.

Konsep AR sendiri pertama kali diperkenalkan oleh Thomas P. Caudell pada tahun 1990 dalam The Term 'Augmented Reality'. Ada tiga karakteristik yang menyatakan suatu teknologi menerapkan konsep AR:

1. Mampu mengkombinasikan dunia nyata dan dunia maya.

2. Mampu memberikan informasi secara interaktif dan realtime.

3. Mampu menampilkan dalam bentuk tiga dimensi.

AR dapat digunakan untuk membantu memvisualisasikan konsep abstrak untuk pemahaman dan struktur suatu model objek. Saat ini AR banyak digunakan dalam bidang game, kedokteran, dan image processing, sedangkan dalam bidang pendidikan masih jarang digunakan.

Sutherland (1968) seorang peneliti yang telah mengembangkan berbagai perangkat dimana pengguna dapat melihat, mendengar, dan menyentuh objek yang ada di dunia maya mulai dari simulasi yang penuh imajinatif hingga teknologi yang menambah interaksi pengguna dengan dunia maya serta dunia nyata. Beberapa aplikasi AR dirancang untuk memberikan informasi yang lebih detail pada pengguna dari objek nyata. Sebagai contoh adalah Ultrasonografi (USG) untuk melihat keadaan kandungan seorang wanita, dan gerak yang sedang dilakukan oleh janin yang ditampilkan dalam sebuah layar secara langsung dan realtime dengan memanfaatkan teknologi ultrasonic. Pendekatan serupa juga memungkinkan ahli bedah plastik untuk merancang bangun rekonstruksi wajah. Dokter bedah secara langsung dan bersamaan dapat merasakan jaringan lunak pasien dan memeriksa secara tiga dimensi dengan proyeksi.

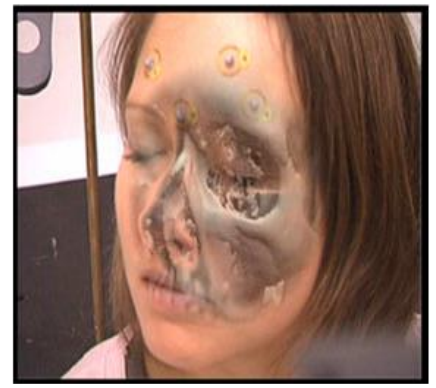

Gambar 1. Proyeksi Rekonstruksi Wajah (Sumber: Augmented Reality Technologies, Systems and Aplicatins)

Menurut Stephen Cawood \& Mark Fiala dalam bukunya yang berjudul Augmented reality: a practical guide, mendefinisikan bahwa Augmented Reality merupakan cara untuk mengeksplorasi objek tiga dimensi dan data, AR merupakan suatu konsep perpaduan 
antara virtual reality dengan world reality. Sehingga objek- objek virtual dua dimensi atau tiga dimensi seolah-olah terlihat nyata dan menyatu dengan dunia nyata. Pada teknologi AR, pengguna dapat melihat dunia nyata yang ada di sekelilingnya dengan penambahan objek virtual yang dihasilkan oleh komputer.

Augmented Reality bertujuan menyederhanakan berbagai hal untuk pengguna dengan membawa informasi virtual ke dalam lingkungan pengguna (Elisa Usada, 2014:83). AR meningkatkan persepsi pengguna dan interaksi dengan dunia nyata. Berikut gambaran umun tentang proses cara kerja augmented reality yang menggunakan webcam dan komputer sebagai medianya.

Tahun 1975 seorang ilmuwan bernama Myron Krueger menemukan video place yang memungkinkan pengguna, dapat berinteraksi dengan objek virtual untuk pertama kalinya. Tahun 1989, Jaron Lanier, memeperkenalkan Virtual Reality dan menciptakan bisnis komersial pertama kali di dunia maya. Kemudian pada tahun 1992 mengembangkan Augmented Reality untuk melakukan perbaikan pada pesawat boeing, dan pada tahun yang sama.

Pada tahun 1992, LB Rosenberg mengembangkan salah satu fungsi sistem $A R$, yang disebut Virtual Fixtures, yang digunakan di Angkatan Udara AS Armstrong Labs, dan menunjukan manfaatnya bagi manusia. Pada tahun yang sama, Steven Feiner, Blair Maclntyre dan dorée Seligman juga memperkenalkan untuk pertama kalinya Major Paper sebagai perkembangan prototype AR.

Pada tahun 1999, Hirokazu Kato mengembangkan ArToolkit di HITLab dan didemonstrasikan di SIGGRAPH. Pada tahun 2000, Bruce $\mathrm{H}$ Thomas mengembangkan ARQuake, sebuah mobile game AR yang ditunjukan dalam International Symposium on Wearable Computers.

Pada tahun 2008, Wikitude AR Travel Guide, memperkenalkan Android G1 Telephone yang berteknologi AR, dan tahun 2009 Saqoosha memperkenalkan FLARToolkit yang merupakan perkembangan dari ArToolkit. FLARToolkit memungkinkan kita memasang teknologi AR di sebuah website, karena output yang dihasilkan FLARToolkit berbentuk Flash. Ditahun yang sama, Wikitude Drive meluncurkan sistem navigasi berteknologi AR di Platform Android. Tahun 2010, Acrossair menggunakan teknologi AR pada I-Phone 3GS.

\section{PEMBAHASAN \\ Pembelajaran dan Media Pembelajaran}

Pembelajaran pada hakekatnya digunakan siswa untuk mengembangkan potensi pada dirinya (Susilana dan Riyana, 2008:1). Kegiatan pembelajaran melibatkan dua belah pihak yaitu peserta didik sebagai penerima pendidikan dan pendidik sebagai pemberi fasilitas. Keutamaan dalam kegiatan pembelajaran adalah terjadinya proses belajar (Susilana dan Riyana, 2008:1). Menurut Sanaky (2013:3), pembelajaran merupakan suatu proses interaksi antara pembelajar, pengajar dan bahan ajar. Kustandi dan Sutjipto (2013:1), mengemukakan bahwa pembelajaran merupakan proses suatu rencana dalam rangka mengelola sumber belajar agar terjadi proses belajar pada siswa. Suprihatiningrum (2013:75), mendefinisikan pembelajaran sebagai serangkaian kegiatan yang yang terencana dengan melibatkan informasi dan lingkungan untuk mempermudah siswa dalam belajar. Pembelajaran adalah kegiatan terencana seorang pendidik yang melibatkan bahan ajar, sumber ajar, informasi, dan lingkungan untuk menciptakan terjadinya proses belajar pada peserta didik sehingga dapat mengembangkan potensi diri, pengetahuan, keterampilan, dan nilai-nilai positif.

Media berasal dari bahasa latin yang berarti perantara atau pengantar. Media diartikan sebagai segala sesuatu yang dapat menyalurkan pesan dari pengirim menuju penerima dengan tujuan untuk merangsang perhatiaan menerima (Sadiman dkk, 2011:6-7). Menurut Bovee dalam Sanaky (2013:3), media merupakan sebuah alat yang berfungsi menyampaikan pesan. Schram (1997) dalam Susilana dan Riyana (2008:5), 
mengemukakan bahwa media merupakan teknologi pembawa pesan sebagai perluasan dari pemberi pesan. Heinich (1993) dalam Susilana dan Riyana (2008:6), mendefinisikan media sebagai alat saluran untuk melakukan interaksi. Media merupakan sebuah alat atau objek yang berfungsi sebagai penghubung antara penerima dan pengirim pesan.

Sukiman (2012:29) media pembelajaran adalah segala sesuatu yang dapat digunakan untuk menyalurkan pesan dari pengirim ke penerima sehingga merangsang pikiran, perasaan, perhatian dan minat serta kemauan peserta didik sedemikian rupa sehingga proses belajar terjadi dalam rangka mencapai tujuan pembalajaran secara efektif. Menurut Bruner (1996: 10-11) dalam Arsyad (2013:11) ada tiga tingkatan utama modus belajar, yaitu pengalaman langsung, pengalaman piktatoral, dan pengalaman abstrak. Agar proses belajar mengajar dapat berhasil dengan baik, siswa sebaiknya diajak untuk memanfaatkan semua alat inderanya (Arsyad,2013).

Media pembelajaran dapat diartikan sebagai alat yang berfungsi dan berguna untuk menyalurkan pesan pembelajaran (Sanaky, 2013:3). Menurut Daryanto (2014:4) media pembelajaran sebagai suatu alat bantu dan bahan dalam proses pembelajaran. Munadi (2013:7) mengemukakan media pembelajaran sebagai segala sesuatu yang dapat menyalurkan pesan dari sumber secara terencana sebagai upaya untuk menciptakan proses belajar yang efektif dan efisien. Sehingga media pembelajaran merupakan suatu perantara antara pendidik dengan peserta didik dalam pembelajaran yang mampu menghubungkan, memberi informasi dan memberi serta menyalurkan pesan sehingga tercipta proses pembelajaran efektif dan efisien.

Kustandi dan Sutjipto (2013:19), kedudukan media dalam sistem pembelajaran adalah sebagai alat bantu, alat penyalur pesan, alat penguatan, dan wakil guru dalam menyampaikan informasi secara teliti, jelas, dan menarik. Menurut Daryanto (2011:6) media pembelajaran menempati posisi yang sangat penting dalam pembelajaran. Media pembelajaran mengakibatkan terjadinya sebuah komunikasi antara pendidik dan peserta didik dalam proses pembelajaran. Apabila dalam proses pembelajaran tidak menggunakan media maka tidak akan terjadi proses pembelajaran. Hal ini disebabkan komunikasi antara pendidik dan peserta didik berlangsung secara tidak optimal. Media menjadi perantara untuk menciptakan komunikasi, bertugas untuk mempermudah pendidik dan peserta didik untuk berkomunikasi, sehingga akan terjadi proses belajar mengajar yang mengakibatkan peserta didik akan memahami hal yang diberikan pendidik. Bila materi ajar telah disampaikan maka hasil belajar peserta didik menjadi umpan balik bagi pendidik. Umpan balik tersebut sebagai bahan pertimbangan dalam proses pembelajaran selanjutnya. Media pembelajaran sebagai titik kunci dalam guru dan siswa dapat saling berkomunikasi dengan optimal sebab media pembelajaran adalah sebagai alat bantu, alat penyalur, alat penguat, dan wakil guru dalam menyampaikan informasi secara teliti, jelas, dan menarik. Dengan demikian posisi media pembelajaran merupakan sarana penghubung yang sangat penting antara sisi satu dengan sisi lainnya karena berisi informasi dan pesan dari pendidik kepada peserta didik.

Menurut Munadi (2013:37), fungsi utama media pendidikan adalah sebagai sumber belajar. Media pendidikan dapat menggantikan fungsi pendidik sebagai sumber belajar karena sumber belajar terdiri dari pesan-pesan, orang, bahan, alat, teknik, dan lingkungan yang mempengaruhi hasil belajar peserta didik. Menurut Daryanto (2011:8), media pembelajaran memiliki fungsi sebagai pembawa pesan yaitu dari pendidik ke peserta didik dalam proses pembelajaran. Media menjadi kunci dalam menciptakan interaksi dalam proses pembelajaran. Pendidik menggunakan sebagai langkah untuk membantu peserta didik dalam menerima pesan dari media pembelajaran. 
Menurut Sanaky (2013:7) fungsi media adalah sebagai perangsang pembelajaran, sebab mampu:

1. Menghadirkan objek dan langkah sebenarnya.

2. Membuat duplikasi dari objek sebenarnya.

3. Membuat konsep abstrak menjadi konsep konkret.

4. Memberi kesamaan persepsi.

5. Mengatasi hambatan waktu.

6. Menyajikan ulang informasi secara konsisten.

7. Memberi suasana belajar yang menyenangkan, tidak tertekan, santai, dan menarik sehingga dapat mencapai tujuan pembelajaran.

Levie dan Lents juga berpendapat dalam Arsyad (2011:16-17), mengemukakan bahwa terdapat empat fungsi media pembelajaran yaitu:

1. Fungsi atensi menciptakan perhatian siswa dan menarik siswa untuk fokus pada materi yang ditampilan.

2. Fungsi afektif menciptakan kenyamanan emosi siswa ketika sedang belajar.

3. Fungsi kognitif mempercepat dalam memahami dan mengingat pesan yang ditampilkan.

4. Fungsi kompensatoris mengakomodasi siswa yang lemah dan lambat dalam menerima dan memahami materi yang diberika secara verbal.

Sehingga dapat dilihat media pembelajaran dapat memiliki fungsi sebagai berikut:

1. Menarik perhatian peserta didik.

2. Mengembalikan fokus peserta didik.

3. Memberikan suasana nyaman kepada peserta didik.

4. Menghadirkan objek dan langkah sebenarnya, membuat tiruan dari objek yang sebenarnya, membuat konsep abstrak menjadi konsep yang nyata.
5. Memberikan persepsi, mengatasi hambatan waktu, menyajikan ulang informasi secara konsisten kepada peserta didik.

Media pembejaran sangat bermanfaat dalam proses pembelajaran. Hal ini untuk meningkatkaan kualitas pengetahuan dan kemampuan peserta didik. Menurut Sanaky (2013:5) manfaat media pembelajaran sebagai alat bantu:

1. Dapat menumbuhkan motivasi belajar akibat adanya ketertarikan peserta didik pada media pembelajaran.

2. Dapat memperjelas makna dari materi pembelajaran.

3. Metode pembelajaran dapat bervariasi.

4. Pembelajaran lebih banyak terlibat dalam kegiatan pembelajaran.

Midun dalam Asyhar (2012:40-41) mengemukakan manfaat media pembelajaran sebagai berikut.

1. Media pembelajaran yang bervariasi dapat memperluas cakrawala sajian materi pembelajaran.

2. Menggunakan berbagai jenis media, peserta didik akan memperoleh pengalaman beragam selama proses pembelajaran.

3. Dapat memberikan pengalaman belajar yang konkret dan langsung pada peserta didik.

4. Media pembelajaran dapat memberikan informasi yang akurat dan terbaru.

5. Media pembelajaran dapat menambah kemenarikan tampilan materi sehingga meningkatkan motivasi dan minat serta mengambil perhatian peserta didik untuk fokus.

6. Media pembelajaran dapat merangsang peserta didik untuk berfikir kritis.

7. Dapat meningkatkan efisiensi proses pembelajaran.

8. Dapat memecahkan masalah pendidikan 
Menurut Susilana dan Riyana (2008:9) mengemukakan kegunaan media pembelajaran yaitu:

1. Memperjelas pesan agar tidak terlalu verbalis.

2. Mengatasi keterbatasan ruang, waktu dan daya indera.

3. Menimbulkan gairah belajar, interakasi, lebih langsung antara murid dengan sumber belajar.

4. Memungkinkan anak belajar mandiri sesuai dengan bakat dan kemampuan visual, aditori, dan kinestetik.

5. Memberi rangsangan yang sama, mempersembahkan pengalaman yang menimbulkan persepsi sama.

Menurut Sadiman dkk (2011:17-18) kegunaan media dalam proses pembelajaran diantaranya:

1. Memperjelas penyajian pesan.

2. Mengatasi keterbatasan ruang, waktu, dan daya indera.

3. Mengatasi pasif anak didik.

4. Mengatasi perbedaan lingkungan dan pengalaman baik guru maupun siswa.

Pemanfaatan media pembelajaran dengan AR sangat bermanfaat dalam meningkatkan proses belajar serta minat peserta didik dalam belajar karena dalam AR sendiri memiliki aspek-aspek hiburan yang dapat meningkatkan minat peserta didik dalam belajar dan bermain serta memproyeksikannya secara nyata dan melibatkan interaksi seluruh panca indera peserta didik dengan teknologi AR ini. Hal ini disebabkan karena AR memiliki karakteristik serta fungsi yang hampir sama dengan media pembelajaran yaitu berfungsi menyampaikan informasi antara penerima dan pengirim atau pendidik dengan peserta didik, dapat memperjelas penyampaian informasi yang diberikan pendidik dan peserta didik dalam proses pembelajaran, dapat memberikan rangsangan motivasi serta ketertarikan dalam pembelajaran.

\section{Peralatan Pendukung Augmented Reality}

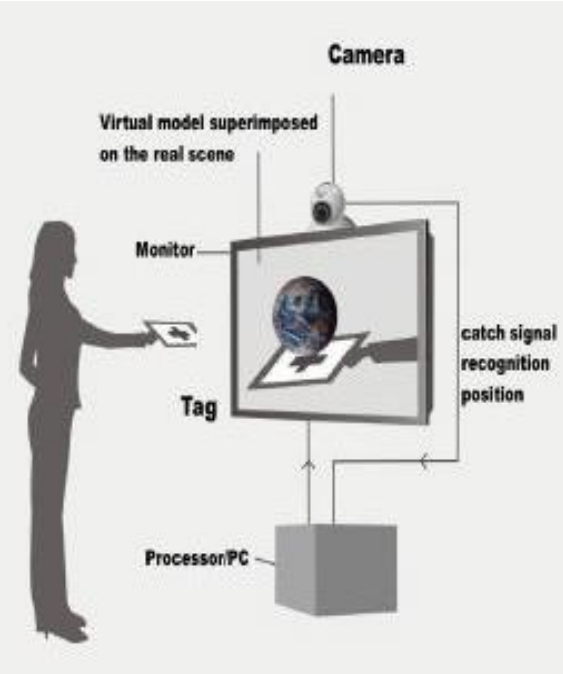

Gambar 2. AR Steps (Sumber: Application of Augmented Reality Technology for Interior Design)

Untuk menjalankan sistem AR, minimal terdiri atas kamera, perangkat display, dan dalam kasus-kasus tertentu memerlukan perangkat khusus untuk berinteraksi dengan objek virtual.

Perangkat utama yang dibutuhkan untuk menjalankan aplikasi berbasis AR, yaitu display, perangkat input tracking, dan komputer seperti yang diungkapkan oleh Carmigniani dalam "main device for augmented reality are dissplay, input device, tracking, computer" (Carmigni et al, 2010).

Perangkat display digunakan untuk menampilkan gambar atau output hasil proses komputer. Ada tiga jenis display dalam AR yang pertama HMD (Head Mounted Device) yaitu sebuah display yang dipakai kepenggunaannya untuk menampilkan gambar hasil penggabungan lingkungan virtual dengan lingkungan nyata (Carmigniani et al, 2010). Bentuknya bisa seperti helm, atau seperti kacamata yang merupakan handheld display yaitu semacam perangkat genggam yang memiliki kemampuan menampilkan 
gambar sekaligus kemampuan proses data dan kemampuan input dan tracking, contohnya seperti smartphone, dan PDA (Carmigniani et al, 2010). Terakhir adalah spasial $A R$, dimana citra visual langsung ditampilkan ke objek fisik tanpa penggunanya harus membawa perangkat display, pada spatial augmented reality perangkat disiapkan pada satu tempat dan tidak dapat dipindah pindahkan seperti pada handheld display, atau HMD (Carmigniani et al, 2010).
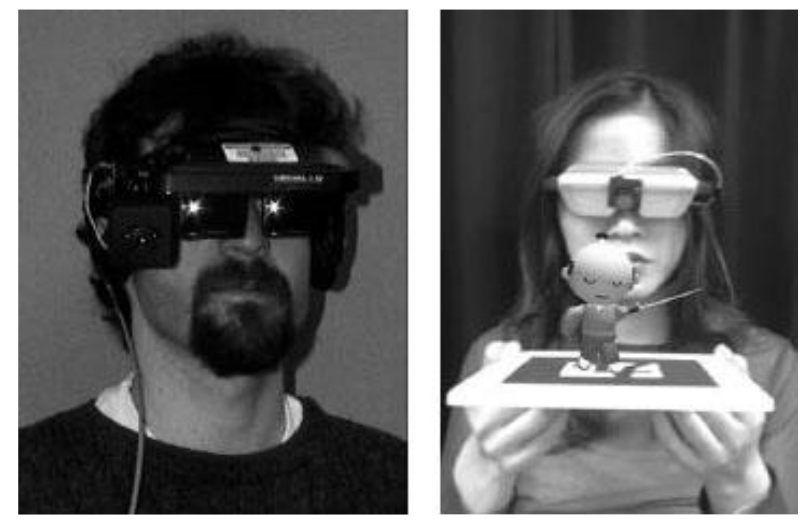

Gambar 3. Penggunaan HMD dalam Sistem (Sumber: Teknologi Augmented Reality, Yuri Yudhaswana Joefrie)

Cara kerja AR terbagi dua macam berdasarkan metode yaitu:

\section{Marker Augmented Reality}

Marker biasanya merupakan ilustrasi hitam dan putih persegi dengan batas hitam tebal dan latar belakang putih. Komputer akan mengenali posisi dan orientasi marker dan menciptakan dunia virtual 3D yaitu titik $(0,0,0)$ dan 3 sumbu yaitu X,Y,dan Z. Marker Based Tracking ini sudah lama dikembangkan sejak 1980-an dan pada awal 1990-an mulai dikembangkan untuk penggunaan Augmented Reality.

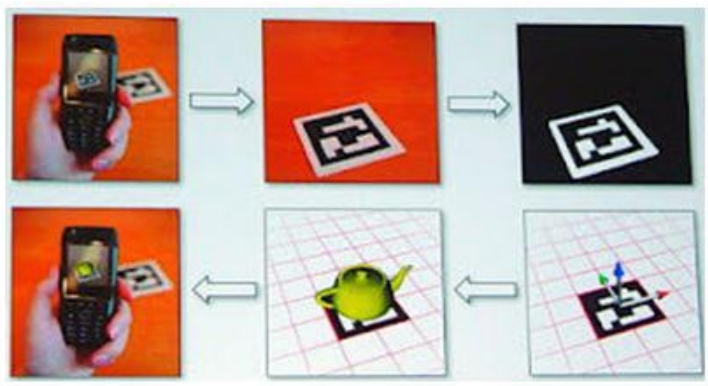

Gambar 5. Cara Kerja Marker AR (Sumber: Augmented Reality E-Resource Berbasis Konten Lokal, Peluang, Masalah dan Tantangan, Studi Kasus pada Perpustakaan Nasional RI)

2. Markerless Augmented Reality

Metode ini pengguna tidak perlu lagi menggunakan sebuah marker untuk menampilkan elemen-elemen digital. Saat ini markerless Augmented Reality banyak dikembangkan oleh perusahaan-perusahaan besar, mereka telah membuat aplikasi AR dengan berbagai macam teknik Markerless Tracking sebagai teknologi andalan mereka, seperti Face Tracking, 3D Object Tracking, dan Motion Tracking.

- Face Tracking Face Tracking merupakan markerless AR yang menggunakan algoritma yang dikembangkan sehingga komputer dapat mengenali wajah manusia secara umum dengan cara mengenali posisi mata, hidung, dan mulut manusia, kemudian akan mengabaikan objek-objek lain di sekitarnya seperti pohon, rumah, dan bendabenda lainnya.

- 3D Objectt Tracking

Berbeda dengan Face Tracking yang hanya mengenali wajah manusia secara umum, teknik $3 D$ Object Tracking dapat mengenali semua bentuk benda yang ada disekitar, seperti mobil, meja, televisi, dan lain-lain.

- Motion Tracking

Teknik komputer ini dapat menangkap gerakan, Motion 
Tracking telah mulai digunakan secara ekstensif untuk memproduksi film-film yang mencoba mensimulasikan gerakan.

- GPS Based Tracking

Teknik GPS Based Tracking saat ini mulai populer dan banyak dikembangkan pada aplikasi smartphone (iPhone dan Android). Dengan memanfaatkan fitur GPS dan kompas yang ada didalam smartphone, aplikasi akan mengambil data dari GPS dan kompas kemudian menampilkannya dalam bentuk arah yang kita inginkan secara realtime, bahkan ada beberapa
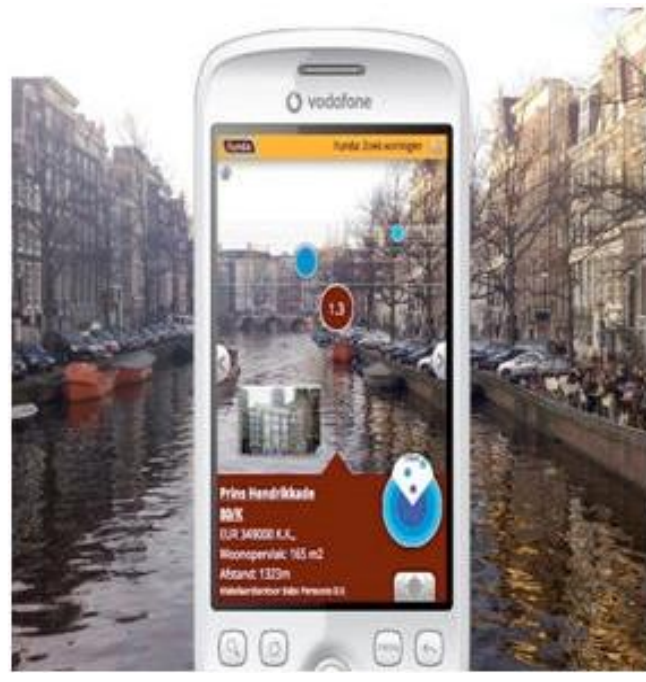

Gambar 6. Handheld Display Device aplikasi menampikannya dalam bentuk 3D.

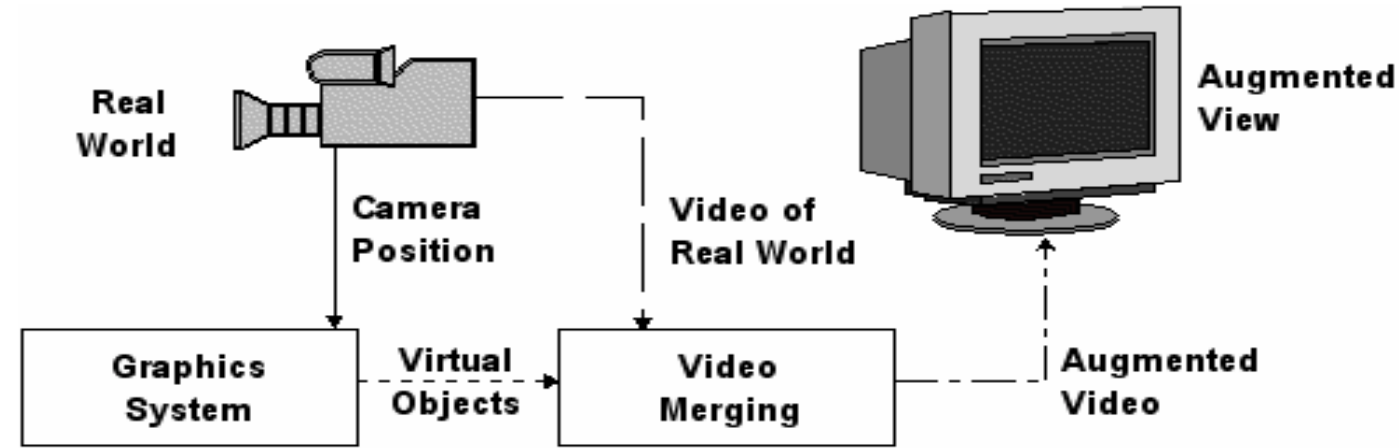

Gambar 7. Perangkat pendukung sistem AR (Sumber: Teknologi Augmented Reality, Yuri Yudhaswana Joefrie)

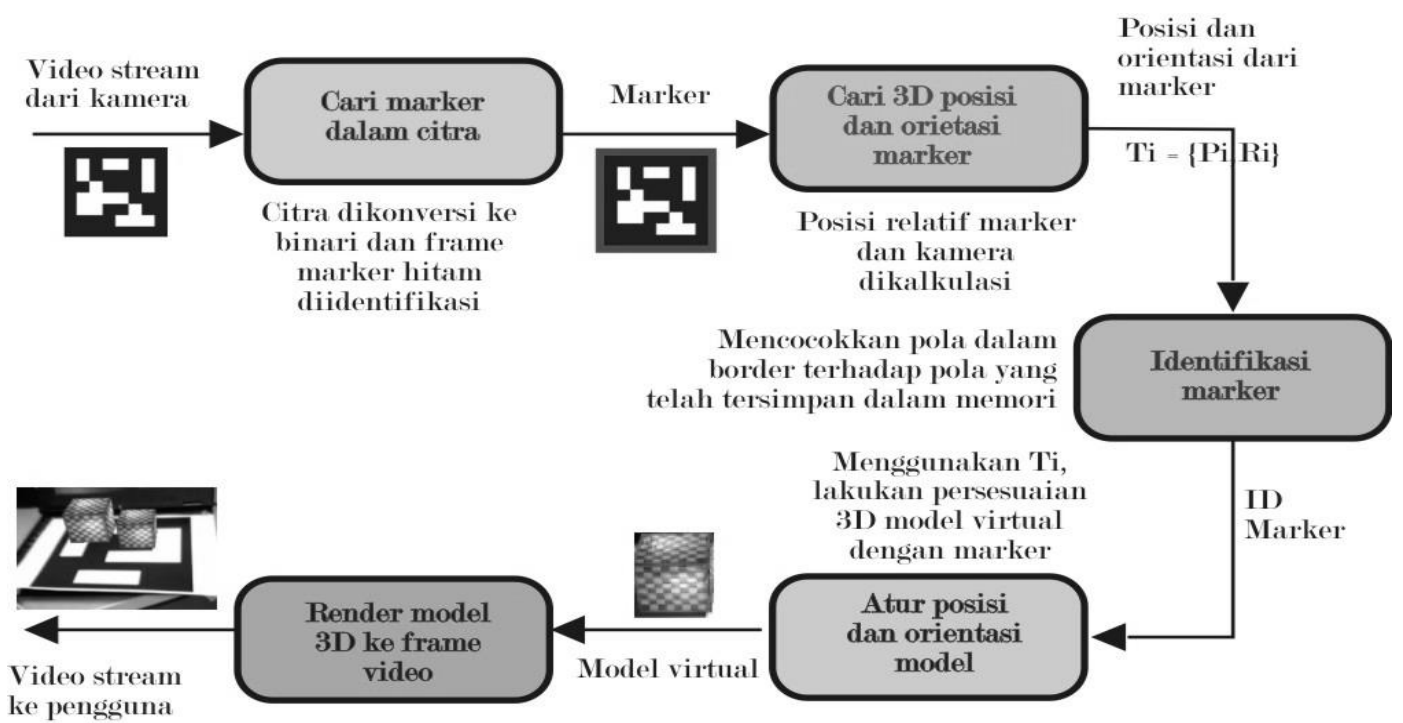

Gambar 8. Langkah-langkah untuk Merender Objek Virtual dalam Dunia Nyata (Sumber: Teknologi Augmented Reality, Yuri Yudhaswana Joefrie) 


\section{SIMPULAN DAN SARAN}

Penggunaan Augmented Reality
sangat berguna untuk media
pembelajaran yang interaktif dan nyata
serta secara langsung oleh peserta didik.
Selain itu media pembelajaran menggunakan Augmented Reality dapat meningkatkan minat peserta didik dalam belajar karena sifat dari Augmented Reality yang menggabungan dunia maya yang dapat meningkatkan imajinasi peserta didik dengan dunia nyata secara langasung. Augmeneted Reality bersifat interaktif yang membuat peserta didik untuk melihat keadaan secara nyata dan langsung serta dapat mengimajinasikan hasil proses pembelajaran yang diberikan pendidik kepada peserta didik.

Pemanafaatan media pendidikan menggunakan Augmented Reality dapat merangsang pola pikir peserta didik dalam berpikiran kritis terhadap sesuatu masalah dan kejadian yang ada pada keseharian, karena sifat dari media pendidikan adalah membantu peserta didik dalam proses pembelajaran dengan ada atau tidak adanya pendidik dalam proses pendidikan, sehingga pemanfaatan media pendidikan dengan augemented reality dapat secara langsung memberikan pembelajaran dimanapun dan kapanpun peserta didik ingin melaksanakan proses pembelajaran. Media Pembelajaran AR dapat memvisualisasikan konsep abstrak untuk pemahaman dan struktur suatu model objek memungkinkan AR sebagai media yang lebih efektif sesuai dengan tujuan dari media pembelajaran.

\section{DAFTAR PUSTAKA}

Antti Ajanki, et.al.2011. "An augmented reality interface to contextual information".Virtual Reality. Vol.15 p161-173

Arsyad, Azhar.2013.Media Pembelajaran Edisi Revisi, Jakarta: PT. Rajagrafindo Persada

$\begin{array}{cr}\text { Asyhar, Rayanda. 2012. } & \begin{array}{r}\text { Kreatif } \\ \text { Mengembangkan }\end{array}\end{array}$
Pembelajaran. Jakarta: Gaung Persada (GP) Press Jakarta.

B. Hoff, R. Azuma.2000."Autocalibration of an Electronic Compass in an Outdoor Augmented Reality System" Proc. Int'I Symp. Augmented Reality 2000 (ISAR'00). pp. 159-164.

Daryanto. 2011. Media Pembelajaran. Bandung: Nurani Sejahtera.

Daryanto. $2014 . \quad$ Pendekatan Pembelajaran Saintifik Kurikulum 2013. Jakarta: Gava Media.

Hujair. AH. Sanaky. 2013. Media Pembelajaran Interaktif-Inovatif. Yogyakarta: Kaukaba Dirpantara.

Krueger, M.1983.Artificial Reality. NY: Addison-Wesley.

Kustnadi, Cecep \& Sutjipto, Bambang. 2013. Media Pembelajaran. Bogor: Galia Indonesia.

Kustnadi, Cecep \& Sutjipto, Bambang. 2013. Media Pembelajaran Manual Digital Edisi Kedua. Bogor: Galia Indonesia

Munadi, Yudhi. 2013. Media Pembelajaran. Jakarata: Referensi.

Munadi, Yudhi. 2013. Media Pembelajaran : Sebuah Pendekatan Baru. Jakarta: Referensi.

R. Azuma.1997."A Survey of Augmented Reality," Presence: Teleoperators and Virtual Environments vol. 6, no. 4,pp. 355-385.

R. Azuma, et. al.1999. "Tracking in unprepared environments for augmented reality systems" Computers \& Graphics vol. 23, no. 6, pp. 787-793.

R. Behringer, et. al..2000 "A Wearable Augmented Reality Testbed for Navigation and Control, Built Solely with Commercial-Off-The-Shelf 
(COTS) Hardware" Proc.Int'l Symp. Augmented Reality 2000 (ISAR'00). Munich,5-6 Oct. 2000, pp. 12-19.

Rudi, Susilana., Cepi, Riyana. 2008. Media Pembelajaran. Bandung: CV Wacana Prima

Sudarmilah, E. Ferdiana, R. Nugroho, L. E. and Susanto, A. 2013. Tech review: Game platform for upgrading counting ability on Preschool Children. Prosidingon The 5th International Conference on Information Technology and Electrical Engineering (ICITEE 2013).

Sulaiman. 2012. Pengembangan Sistem Evaluasi. Yogyakarta: Insan Madani.

Suprihatiningrum, Jamil. 2013. Strategi Pembelajaran Teori dan Aplikasi. Yogyakarta: AR RUZZ MEDIA.

Vallino, James R. (April 1998). Interactive Augmented Reality. Rochester, New York: University of Rochester. hlm. 6-8. 